\title{
Participação, oportunidades e interesses
}

\author{
Ligia Helena Hahn Lüchmann*
}

\section{Introdução}

Pretendo aqui discutir o tema da participação política enquanto processo no qual a população toma parte (ativamente e de formas variadas) nos processos de decisão política. Tendo em vista que esta perspectiva de participação pressupõe que os processos decisórios sejam resultantes da discussão pública coletiva e plural, o conceito de democracia deliberativa parece reunir de forma mais articulada as características deste tipo de participação enquanto modelo ou ideal democrático que, diferente da democracia representativa, caracterizada por conferir a legitimidade do processo decisório ao resultado eleitoral, advoga que a legitimidade das decisões políticas advém de processos de discussão orientados pelos princípios da inclusão, do pluralismo, da igualdade participativa, da autonomia e do bem-comum, conferindo um papel ativo à sociedade civil tendo em vista um reordenamento na lógica de poder tradicional.

$\mathrm{Na}$ medida em que várias experiências participativas, principalmente Conselhos Gestores e Orçamento Participativo (OP), vêm sendo implementa-

* Doutora em Ciências Sociais pela Unicamp, professora na Ufsc; áreas de pesquisa: sociedade civil, orçamento participativo; Mail: ligia@cfh.ufsc.br.

\begin{tabular}{|l|l|l|l|l|l|}
\hline Civitas & Porto Alegre & v. 6 & n. 1 & jan.-jun. 2006 & p. 119-129 \\
\hline
\end{tabular}


das e institucionalizadas no país, nas últimas décadas, parece bastante compreensível - e justificável - a incorporação deste referencial teórico para a análise das possibilidades e limites desses espaços participativos enquanto exemplos de democracia deliberativa.

Entretanto, mesmo se admitindo que estas experiências possam ser ainda consideradas uma espécie de rascunho se observadas a partir de uma lente histórica mais alargada, a recorrência de problemas e limites apontada pela bibliografia especializada vem suscitando a adoção de posturas analíticas não apenas mais cuidadosas e criteriosas, como fundamentalmente mais questionadoras acerca do caráter democrático que estas experiências aparentemente destilam. Dentre o conjunto de questões que as análises inspiram, é preciso indagar acerca da justeza entre os princípios normativos dados pela teoria e os elementos de realidade fornecidos pela empíria. Esta indagação é reforçada quando se está tratando da participação em uma realidade (política, econômica, social e cultural) atravessada por históricas relações de controle, subordinação, autoritarismo e desigualdades sociais. Frente a este quadro, a pergunta central é se é possível, em realidades como a brasileira, a realização da democracia deliberativa.

Uma resposta mais apurada a esta questão certamente exigiria a realização de amplas e complexas pesquisas de base comparativa, cruzando dados e variáveis cujo grau de sofisticação parece ainda longe de ser alcançado. Diferente disso, o que procuro aqui é levantar algumas reflexões sobre alguns dos principais problemas e críticas levantados pela literatura sobre estes processos de participação. Dentre estes problemas da participação, procuro avaliar alguns aspectos acerca das questões (e inter-relações) que dizem respeito à apatia, às oportunidades e desigualdades (renda, escolaridade, organização, capacidade comunicativa) e os diferentes interesses sociais (pluralidade).

\section{Problemas e críticas aos processos de participação política deliberativa}

É bastante visível que, de um processo de euforia com o advento das experiências participativas caracterizado por estudos que acentuam as suas novidades e potencialidades democráticas, se passe cada vez mais a um processo de avaliação que vem apontando os seus limites. Assim, os estudos 
mais recentes carregam um teor analítico mais crítico frente à constatação de inúmeros problemas que margeiam estas experiências, principalmente aquelas relacionadas ao campo conselhista (conselhos gestores de políticas públicas). Mesmo em se tratando de experiências em diferentes esferas e dotadas de especificidades locais, a repetição dos problemas instiga análises que transcendem as fronteiras territoriais. Dois trabalhos são ilustrativos na medida em que, ao analisarem experiências em diferentes contextos nacionais, apontam um quadro variado de problemas que parece se replicar em grande parte de nossas experiências locais.

O primeiro trabalho (Font, 2004) apresenta uma sistematização dos principais problemas que vêm sendo apontados na literatura, com ênfase nas características dos cidadãos participantes. As avaliações se reportam, de maneira geral aos seguintes problemas:

- os cidadãos, de fato, não querem participar ou se envolver em processos complicados e fastigantes que constituem os espaços de decisão pública;

- os cidadãos, quando participam, o fazem de forma inconstante, o que dificulta ou impede a garantia de um funcionamento regular das instâncias participativas;

- os cidadãos dispostos a participar são sempre os mesmos, constituindo uma minoria que se perpetua nos espaços decisórios;

- de maneira geral, os cidadãos participam mais ativamente somente em situações de conflito que requerem e motivam a mobilização;

- na maioria dos casos, os cidadãos que participam representam eles próprios, ou seja, seus interesses, ou os interesses muito particulares de grupos ou setores sociais.

No segundo trabalho, Fung e Wright (1999) sistematizam um conjunto de críticas à democracia deliberativa ressaltando:

- a tendência das instituições políticas participativas caírem vítimas de interesses particulares;

- o risco de "balcanização" enquanto prevalecimento de facciosismos ou da dominação de determinados grupos nos processos decisórios; 
- o problema da representação política justa, ou dos riscos de elitização da participação;

- a desatenção (da democracia deliberativa) aos problemas de poder e dominação em virtude de sua ênfase aos aspectos conciliatórios e dialógicos em detrimento dos conflitos de base antagonista;

- a vulnerabilidade da participação à apatia popular;

- e por fim, a precariedade na garantia de estabilidade e sustentabilidade institucional, principalmente frente às resistências de atores e instituições convencionais (políticos, burocratas, funcionários etc.).

Dentre a variedade de questões que atravessam - e sustentam - estes conjuntos de críticas e problemas, destaco aqui: a alegada apatia política da população, e as diferenças de interesse e poder que ameaçam a constituição de consensos publicamente compartilhados. O que proponho, a seguir, é avaliar, à luz das experiências de conselhos e OPs, a pertinência destas avaliações.

\section{Apatia, racionalidade, desigualdades e oportunidades participativas}

Embora recorrente na teoria política, o tema dos motivos da participação política é recheado de controvérsias e variações analíticas. De acordo com Sani (1992), embora ainda não se tenha elaborado uma teoria plausível que consiga explicar a variedade de resultados acerca da participação política, os estudos indicam um conjunto de características relativamente constantes acerca do perfil dos participantes:

Em geral, os resultados indicam que os níveis de participação política são mais elevados entre os homens, nas classes altas, nas pessoas de mais elevado grau de instrução, nos centros urbanos mais que nas zonas agrícolas, entre pessoas educadas em famílias onde a política ocupa um lugar de relevo, entre os membros de organizações ligadas mesmo indiretamente à política, entre os que estão mais facilmente expostos a contatos com pessoas ou ambientes politizados etc. (ibidem, p. 890).

Com algumas variações, este perfil (gênero, renda, escolaridade, vínculo político) parece se reproduzir no conjunto de experiências conselhistas do país, através de um processo de "elitização" caracterizado pela constituição 
de ciclos (viciosos) de participação e representação em que os mais cultos, organizados e com recursos materiais assumem os espaços de representação social, espaços estes que tendem a refinar (e reafirmar) o seu estoque de informação e qualificação (técnica e política) perante as "bases" sociais.

Dentre o conjunto de explicações para esse processo de elitização, cabe aqui recuperar duas importantes considerações: o resgate da racionalidade que se esconde por trás da aparência de apatia, passividade e manipulação; e a questão dos custos e oportunidades da participação.

No que diz respeito à racionalidade (ou racionalidades), convém resgatar algumas análises que, de forma diferente, dão importantes pistas para se pensar a tão propalada apatia nos processos de participação. Analisando a estrutura organizacional das associações de moradores, Fontes (1996) avalia o processo de profissionalização e burocratização das mesmas partindo de uma premissa que, diferente de uma aparente apatia e desmobilização popular, resgata uma racionalidade pautada na "disposição dos moradores de deixarem seus líderes instrumentalizarem politicamente seus interesses - afinal de contas, eles recebem benefícios indiretos pelo exercício do poder" (p. 57) a exemplo do reconhecimento e do prestígio na comunidade; benefícios materiais como recursos, emprego; acesso especial a pessoas de influência, entre outros. Nesta troca, é inevitável que as lideranças se especializem e passem a ocupar os espaços decisórios e de poder.

Em uma outra perspectiva, o questionamento acerca de um suposto conformismo da população é levantado por Valla (2002) a partir de uma avaliação acerca do grau de racionalidade popular que é geralmente desconhecido (ou desconsiderado) por profissionais, teóricos e militantes políticos. De acordo com o autor:

É bem provável que estes setores da população (classes populares) tenham uma enorme lucidez sobre sua situação social, o que pode significar também clareza de que uma melhoria significativa seja uma ilusão. Neste sentido, a crença em melhorias e numa solução mais efetiva pode apenas ser um desejo, embora importante, da classe média comprometida. Isso significaria que a percepção da população seria mais lúcida e realista, a não ser que se configure uma conjuntura com indicações de possibilidades reais de mudança que favoreça as classes populares. 
De diferentes maneiras, este resgate da racionalidade traz à tona uma segunda consideração acerca da participação política que diz respeito aos custos e oportunidades de participação. De acordo com Held (1987), a divisão entre cidadãos ativos e passivos pode estar muito mais relacionada à falta de oportunidades de participação do que a alegada passividade ou emocionalidade natural. ${ }^{1}$ Há evidências, segundo o autor, de que muitas pessoas não participam em virtude da desconfiança e do ceticismo com relação à política, o que parece corroborado pela avaliação de Valla acerca da racionalidade popular. E ainda, a participação envolve custos (Pateman, 1992) que impedem ou inviabilizam a inclusão de grandes contingentes populacionais que, no caso do Brasil, se encontram na categoria de subcidadãos (cf. Souza, 2003), o que implica uma massa de indivíduos que, se não são excluídos por problemas materiais, são silenciados por procedimentos que requerem importantes graus de destreza comunicativa e organizativa. E, por último, há que se destacar a importância da abertura de oportunidades à participação, que está também inter-relacionada à questão dos tipos de problemas e demandas em questão. Seguindo ainda análise de Held (1987), o sentimento de impotência perante a política tende a se afrouxar quando as pessoas são chamadas a participar das questões que dizem respeito a sua vida e que percebam importantes graus de confiabilidade nos espaços participativos.

Não é à-toa, portanto, que as experiências de OP têm apresentado maior capacidade de mobilização e de ampliação da participação. Não apenas em função de que se constitui em uma oportunidade de discussão e definição das prioridades sociais que diminui, em função de seu desenho institucional (que oportuniza a participação de indivíduos e associações nos bairros e regiões), os custos de participação, como em função dos impactos no aumento do grau de confiança a partir do "efeito-demonstração". O perfil dos participantes

Sustentada pelas teorias realistas ou elitistas da democracia.

2 Analisando o OP de Porto Alegre, Abers (1997) ressalta a importância do "efeitodemonstração". Os primeiros bairros a receber investimentos do OP foram os historicamente conhecidos pela sua maior capacidade de organização, sendo que, ao longo do tempo e com a incorporação dos critérios de distribuição dos recursos, a população passa crescentemente a se mobilizar e perceber o OP como meio para obter as melhorias em seus bairros. Através do efeito-demonstração, muitos bairros se mobilizam e novas associações são criadas, sendo que a percepção, por parte dos não-participantes, de que a mobilização e organização são recompensadas com investimentos públicos nos bairros têm se configurado como importante elemento motivador da participação. A importância do efeito-demonstração pode ser percebida 
das experiências de OP também reflete uma relativa inibição ao processo "natural" de elitização, na medida em que, de maneira geral, são os pobres (embora não os mais pobres) que participam. Além da confiança e da ampliação de oportunidades de participação promovidas pelo OP, outros dois elementos a destacar têm a ver com as diferenças de perspectivas e interesses (ou o pluralismo) e o tipo de problemas a resolver (ou as diferenças de políticas).

\section{Diferenças de políticas participativas e de interesses}

Como vimos, apatia e desigualdades sociais são elementos que, embora limitadores da participação, podem ser relativizados ou atenuados através da implementação de processos que oportunizem a participação e desbloqueiem, na medida do possível, os mecanismos históricos de reprodução da apatia e de elitização da política.

Um segundo elemento que atravessa estes espaços e dinâmicas participativas diz respeito ao pluralismo, ou às diferenças de interesses, perspectivas e valores sociais. Um dos pilares da democracia deliberativa, o pluralismo constitui-se como princípio caracterizado pela idéia de que todos são cidadãos com os mesmos direitos, independente de sua inserção social, política, religiosa, econômica e cultural. A acentuada ênfase nos riscos de "balcanização" e de captura dos procedimentos deliberativos pelos interesses particulares (de indivíduos, grupos ou instituições) atesta as dificuldades de conciliação entre pluralismo e interesse comum. Aqui, diferente das experiências de $\mathrm{OP}$, os conselhos gestores tendem a apresentar ou explicitar de forma mais dramática essas dificuldades de conciliação de interesses, de negociação e diálogo entre os diferentes sujeitos participativos. De maneira geral, os estudos (cf. Tatagiba, 2002) indicam que as experiências conselhistas apresentam sérios problemas por serem atravessadas por interesses antagônicos e/ou inconciliáveis. Embora prevejam uma composição de base plural, as artima-

se comparados os números da participação ao longo do tempo, ou entre os primeiros anos do $\mathrm{OP}$, quando as expectativas foram frustradas e as obras não-realizadas, e os anos subseqüentes, após a reestruturação financeira e o início da execução das obras. Foi a partir do terceiro ano que a participação se generalizou, incorporando centenas, senão milhares de novos participantes que entram em cena na medida em que percebem que sua participação significa a possibilidade de mudanças efetivas em suas condições de vida. 
nhas políticas tendem a esvaziar o caráter de publicidade deliberativa destes espaços. Além do desenho institucional, que reduz as oportunidades e aumenta os custos da participação (Lüchmann, 2002a) e que tende a um processo de elitização, há que se ressaltar a influência do tipo de política em jogo e da capacidade de obtenção de consensos, ou de conciliação de interesses destes espaços. Uma comparação entre o OP e os conselhos parece novamente bemvinda.

Por tratar de questões que afetam de forma mais direta a população e notadamente os setores mais carentes e dependentes dos serviços estatais o OP apresenta um importante potencial de motivação à participação. Além disso, a participação e a adesão ao processo do orçamento participativo revelam uma coincidência de interesses sociais e políticos através dos objetivos e resultados do OP, que vem se mostrando como alternativa confiável de resolução das demandas sociais. Trata-se, portanto, de uma política de soma positiva: o estado mantém e aumenta sua legitimidade e capacidade de implementação de políticas, bem como a população vê atendidas as reivindicações que foram por ela demandadas. Apresenta forte capacidade de formação de consensos não apenas em função deste compartilhamento de interesses, como também de uma maior capacidade de incorporação de lideranças sociais que, compartilhando do mesmo projeto político, passam a atuar no interior da estrutura governamental.

A variável relativa à vontade e comprometimento político é, certamente, um aspecto central e tem se constituído em limite decisivo no desenvolvimento bem-sucedido de experiências conselhistas, na medida em que, em função de prerrogativas legais, os conselhos tendem, em muitos casos, a serem implementadas com fortes resistências do poder político governamental (Dagnino, 2002), diferente das experiências de OP que partem da disposição e da vontade político-institucional. Entretanto, convém aqui apresentar a variável do tipo de política em jogo. No caso dos conselhos gestores que tratam da discussão e definição de políticas mais gerais, o caráter da aproximação e da concreticidade da relação demanda-resolução não se efetiva como no caso das experiências de $\mathrm{OP}$, o que limita (e muito) a motivação à participação. Não é à-toa (ou em função de uma suposta apatia natural da população), portanto, que se observa uma baixa freqüência participativa junto aos conselhos gestores, se comparados ao OP. 
Além disso, nestes espaços, a dimensão do pluralismo dificulta, como já visto, a obtenção de consensos ou a conciliação de interesses, na medida em que prevêem a participação de diferentes setores sociais (mercado, estado e sociedade civil), cujo grau de conflituosidade, de acordo com o perfil e a configuração dos setores participativos, tende a assumir um caráter mais antagonista, e, portanto, menos passível de acordo e negociação. Assim, se os conselhos podem ser considerados (de forma muito apressada e generalizada) espaços com maior grau de pluralidade, se comparados ao OP, apresentam também, e em função deste grau, maiores dificuldades de articulação, diálogo e negociação pública.

É nesta perspectiva que parece bastante oportuna a crítica acerca do caráter pouco impactante destes espaços na promoção de mudanças sociais. A combinação ótima entre as variáveis da capacidade associativa e/ou organizativa da sociedade civil, da vontade política e do desenho institucional (Lüchmann, 2002a; 2002b), parece ainda insuficiente para responder a este desafio, não sendo, portanto, incorretas as críticas que questionam o poder destes espaços em promover mudanças significativas na realidade social. O OP de Porto Alegre, que parece combinar de forma mais efetiva estas três variáveis apresenta, por seu turno, dificuldades quanto a sua capacidade de ampliar (no sentido de pluralizar) o quadro dos atores sociais, e por conseguinte, desafiar importantes antagonismos e interesses políticosociais. Não é, portanto, por acaso que as experiências de OP têm se acomodado relativamente bem à institucionalidade política convencional.

O tipo de política diz muito não apenas no que se refere a maior ou menor proximidade com os interesses da população, como também no que diz respeito ao quadro de alcance social e de complexidade institucional. ${ }^{3}$ O tipo de política e o maior ou menor impacto ou alcance de determinada área da política pública significa a incorporação de outros sujeitos (por exemplo, o setor empresarial), o que significa o enfrentamento com níveis superiores de resistência e conflitos sociais.

3 Soraya Côrtes (2002) analisa, por exemplo, algumas diferenças nas áreas das políticas de saúde e de assistência social que vão impactar diferenças na participação nos respectivos conselhos gestores. 
Assim, embora estas experiências participativas venham se constituindo em avanços significativos na trajetória da construção democrática do país, parece que seus limites estão diretamente conectados ao "o que está em jogo" neste processo, ou na sua capacidade de anestesiar interesses particularistas que acabam, em muitos casos, correndo por fora desses espaços.

\section{Considerações finais}

Embora atravessadas por diferentes dificuldades e limites, algumas experiências participativas brasileiras parecem bastante pertinentes e instigantes para o aprofundamento do debate teórico acerca da democracia deliberativa, na medida em que, entre outros, ao oportunizar a participação dos setores até então excluídos dos processos decisórios, contribuem para a desnaturalização da tese da apatia política da população. $\mathrm{O}$ reconhecimento de diferentes tipos de racionalidade também permite um olhar mais crítico com relação a este axioma. Entretanto, estas novas oportunidades participativas estão ancoradas não apenas em diferentes graus de articulação entre as variáveis: vontade política, desenho institucional e tradição associativa; como também dizem respeito a diferentes tipos de política (e de demandas e complexidade institucional) e de interesses, cujo grau de negociação, conflituosidade e de antagonismo repercute de forma incisiva nos procedimentos e resultados participativos. Assim, o tipo de política do OP e seu potencial de conciliação de interesses (entre governo e setores comunitários, por exemplo) possibilita a ampliação de uma dinâmica participativa que não vem, de maneira geral, acompanhada de uma maior pluralidade societal, como em alguns casos de conselhos gestores que apresentam, em função desta heterogeneidade, grandes dificuldades de obtenção de consensos publicamente partilhados.

\section{Referências}

ABERS, R. Inventing local democracy: neighborhood organizing and participatory policy-making in Porto Alegre - Brazil. Tesis (Doctor of Philosophy) - University of California, Los Angeles, 1997.

CÔRTES, S. M. V. Participação de usuários nos conselhos municipais de saúde e de assistência social de Porto Alegre. In: PERISSINOTTO, R.; FUKS, M. (orgs.). Democracia, teoria e prática. Rio de Janeiro: Relume-Dumará, 2002. 
DAGNINO, E. Sociedade civil, espaços públicos e a construção democrática no Brasil: limites e possibilidades. In: DAGNINO. E. (org.). Sociedade civil e espaços públicos no Brasil. Rio de Janeiro: Paz e Terra, 2002, p. 279-301.

FONT, J. (org.). Ciudadanos y decisiones públicas. Barcelona: Editorial Ariel, 2004.

FONTES, B. A. S. Estrutura organizacional das associações políticas voluntárias. RBCS, São Paulo,ano 11, n. 32, out. 1996.

FUNG, A.; WRIGHT, E. Experimentos em democracia deliberativa. Revista Sociologias, v. 1, n. 2, jul.-dez. 1999.

HELD, D. Modelos de democracia. Belo Horizonte: Paidéia, 1987.

LÜCHMANN, L. H. H. Os conselhos gestores de políticas públicas: desafios do desenho institucional. Revista de Ciências Sociais Unisinos, n. 161, jul.-dez. 2002a, p. 43-79.

- Possibilidades e limites da democracia deliberativa: a experiência do Orçamento Participativo de Porto Alegre. Campinas: Unicamp (Tese de doutorado em Ciências Sociais), 2002b.

PATEMAN, C. Participação e teoria democrática. Rio de Janeiro: Paz e Terra, 1992.

SOUZA, J. A construção social da subcidadania: para uma Sociologia Política da modernidade periférica. Belo Horizonte: Ufmg; Rio de Janeiro: Iuperj, 2003.

SANI, Giacomo. Participação política. In: BOBBIO, N. et al. Dicionário de política. Brasília: UNB, 1992, p. 888-890.

TATAGIBA, L. Os Conselhos gestores e a democratização das políticas públicas no Brasil. In: DAGNINO. E. (org.). Sociedade civil e espaços públicos no Brasil. Rio de Janeiro: Paz e Terra, 2002, p. 47-103.

VALLA, V. V. Controle social ou controle público? Uma contribuição ao debate sobre controle social - Prefácio. In WENDHAUSEN, A. O duplo sentido do controle social: (dês)caminho da participação em saúde. Itajaí: Univali, 2002.

Recebido em 20 de janeiro de 2006 e aprovado em 4 de fevereiro de 2006 